\title{
PENGARUH TANGIBLE DAN RESPONSIVENESS TERHADAP KEPUASAN WAJIB PAJAK KENDARAAN BERMOTOR PADA LAYANAN SAMSAT KELILING BALARAJA KABUPATEN TANGERANG BANTEN
}

\section{THE EFFECT OF TANGIBLE AND RESPONSIVENESS TO THE SATISFACTION OF MOTOR VEHICLE TAXPAYER ON BALARAJA ROVING ONE ROOF SYSTEM IN TANGERANG BANTEN DISTRICT}

\author{
Ratnah \\ Program Studi Manajemen, Fakultas Ekonomi, \\ Universitas Muhammadiyah Tangerang \\ Email: ratnah@gmail.com \\ Muljadi \\ Program Studi Manajemen, Fakultas Ekonomi, \\ Universitas Muhammadiyah Tangerang \\ Email: moeljadi@umt.ac.id
}

\begin{abstract}
ABSTRAK
Penelitain ini dilatarbelakangi oleh adanya ketidakpuasan yang dirasakan oleh wajib pajak kendaraan bermotor dalam melakukan kewajiban membayar pajak. Sehingga UPT BAPENDA Balaraja kabupaten Tangerang Banten harus mencari cara agar wajib pajak merasa puas dan nyaman dalam melaksanakan kewajiban membayar pajak. Beberapa faktor yang dapat meningkatkan kepuasan wajib pajak adalah dengan menggunakan pelayanan yang berkualitas, pengalaman yang positif dan berkesan sehingga wajib pajak merasa senang. Tujuan penelitian ini untuk mengetahui pengaruh tangible dan responsiveness terhadap kepuasan wajib pajak kendaraan bermotor. Populasi dalam penelitian ini adalah wajib pajak kendaraan bermotor yang terdaftar di Kantor Bersama Samsat Balaraja dengan berjumlah 700 unit. Dari jumlah tersebut ditentukan sampel dengan menggunakan tehnik Simple Random Sampling maka diperoleh jumlah sample sebanyak 88 responden. Hasil dari penelitian ini adalah Tangible dan Responsiveness secara simultan berpengaruh signifikan terhadap kepuasan wajin pajak kendaraan bermotor di Samsat Keliling Balaraja. Tangible berpengaruh signifikan terhadap kepuasan wajin pajak kendaraan bermotor di Samsat Keliling Balaraja. Responsiveness berpengaruh signifikan terhadap kepuasan wajin pajak kendaraan bermotor di Samsat Keliling Balaraja.
\end{abstract}

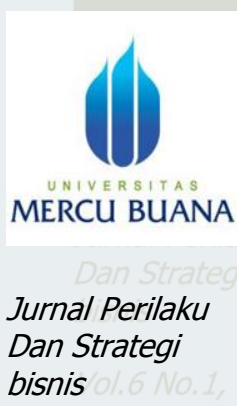

Vol.6 No.1, 2018

Hal. $37-46$

Kata kunci: Tangible, Responsiveness, dan Kepuasan Wajib Pajak Kendaraan Bermotor.

\section{ABSTRACT}

This research is motivated by the dissatisfaction felt by the taxpayer of the motor vehicle in performing their obligation to pay the tax. So that UPT BAPENDA Balaraja Tangerang district of Banten must find a way for taxpayers feel satisfied and comfortable in carrying out the 
obligation to pay taxes. Some factors that can improve taxpayer satisfaction is to use a quality service, a positive experience and memorable so that taxpayers feel happy. The purpose of this study to determine the effect of tangible and responsiveness to satisfaction of motor vehicle taxpayers. The population in this study is the motor vehicle taxpayers registered in the Joint Office One Roof System Balaraja in number of 700 units. From the amount of sample is determined by using Simple Random Sampling technique hence it is obtained amount of sample counted 88 responders. The result of this research is Tangible and Responsiveness simultaneously have a significant effect on satisfaction of motor vehicle taxpayer in Roving One Roof System Balaraja. Tangible has significant effect on satisfaction of motor vehicle taxpayer in Roving One Roof System Balaraja. Responsiveness is significantly influenced the satisfaction of motor vehicle taxpayer in Roving One Roof System Balaraja.

Keywords: Tangible, Responsiveness, and Satisfaction of Motor Vehicle Taxpayer.

\section{PENDAHULUAN}

Fenomena kualitas pelayanan publik di Indonesia tidak lepas dari tuntutan masyarakat terhadap mutu pelayanan instansi pemerintah yang semakin meningkat, dikarenakan masyarakat selalu menuntut pelayanan publik yang berkualitas dari birokrat, meskipun perwujudannya antara kinerja dengan kualitas pelayanan tidak sesuai dengan harapan. Karena pelayanan publik di Indonesia saat ini masih bercirikan rumit, bertele-tele, dan lambat, sehingga membuat para masyarakat enggan untuk mempercayai kualitas pelayanan pemerintah. Salah satu instansi pemerintah yang menyelenggarakan pelayanan publik untuk memperlancar dan mempercepat pelayanan dan kepentingan konsumen yaitu Samsat Keliling. Seiring dengan pergeseran pola pikir dan cara pandang masyarakat terhadap peningkatan pelayanan publik yang lebih bermutu dan berkualitas.

Di Samsat Keliling pun masih memiliki banyak masalah yang harus diperbaiki dalam kualitas pelayanan publik, ini merupakan suatu tantangan besar untuk meningkatkan kepercayaan masyarakat terhadap pemerintah. Masalah yang terjadi di Samsat Keliling ini yaitu, tidak ada petunjuk tentang alur pelayanan sehingga konsumen merasa kebingungan dalam membayar Pajak Kendaran Bermotor (PKB). Konsumen juga merasa kualitas pelayanan yang diberikan masih lambat dan tidak adanya petunjuk persyaratan pembayaran PKB yang harus dilengkapi oleh konsumen, sehingga konsumen harus bertanya kepada wajib pajak yang lain (Hamdani,2016).

Menurut penelitian yang diungkapkan oleh Rusydi dan Fathoni (2011) terbukti bahwa sesuatu yang dapat dilihat oleh wajib pajak seperti ruangan yang nyaman, tidak panas, mempunyai kamar kecil yang sehat, dan beberapa hal yang mencerminkan kualitas pelayanan, maka sangat berpengaruh terhadap kepuasan wajib pajak. Penelitian tersebut didukung oleh Tekol dan Massie (2015) yang menyimpulkan bahwa daya tanggap dalam membantu masyarakat dan memberikan pelayanan dengan tanggap, seperti siap membantu para wajib pajak, kecepatan dalam pelayanan dan komunikasi yang lancar, dan semakin tinggi daya tanggap yang diperlihatkan, maka akan mempengaruhi kepuasan masyarakat. Berdasarkan uraian diatas, Penulis tertarik untuk melakukan penelitian tentang Pengaruh Tangible dan Resposiveness Terhadap Kepuasan Wajib Pajak Kendaraan Bermotor Pada Layanan SAMSAT Keliling Balaraja.

\section{Rumusan Masalah}

1. Apakah Tangible berpengaruh terhadap kepuasan wajib pajak keandaraan bermotor pada layanan SAMSAT Keliling Balaraja?

2. Apakah berpengaruh Responsiveness terhadap kepuasan wajib pajak kendaraan bermotor pada layanan SAMSAT Keliling Balaraja? 
3. Apakah Tangible dan Responsiveness berpengaruh secara simultan terhadap wajib pajak kendaraan bermotor pada layanan SAMSAT Keliling Balaraja?

\section{Tujuan Penelitian}

1. Untuk mengetahui pengaruh Tangible terhadap kepuasan masyarakat saat membayar pajak kendaraan bermotor.

2. Untuk mengetahui pengaruh Responsiveness terhadap kepuasan wajib pajak saat membayar pajak kendaraan bermotor.

3. Untuk mengetahui pengaruh Tangible dan Responsiveness terhadap kepuasan wajib pajak saat membayar pajak kendaraan bermotor.

\section{KAJIAN PUSTAKA \\ Tangible}

Kualitas layanan adalah bentuk aktualisasi nyata secara fisik yang dapat dilihat oleh orang lain. Menurut Sunyoto dan Fatonah (2015:288) Tangible atau berwujud yaitu kemampuan suatu perusahaan dalam menunjukan eksistensinya kepada pihak eksternal. Penampilan dan kemampuan sarana dan prasarana fisik perusahaan yang dapat diandalkan keadaan lingkungan sekitarnya merupakan bukti nyata dari pelayanan yang diberikan oleh pemberi jasa. Sedangkan menurut Parasuraman dkk dalam Bursan dan Chanerie (2012) Tangibles, atau bukti fisik yaitu kemampuan suatu perusahaan dalam menunjukkan eksistensinya pada pihak eksternal. Penampilan dan kemampuan sarana dan prasarana fisik perusahaan dan keadaan lingkungan sekitarnya adalah bukti nyata dari pelayanan yang diberikan oleh pemberi jasa. ini meliputi fasilitas fisik (Gedung, Gudang, dan lainnya), teknologi (peralatan dan perlengkapan yang dipergunakan), serta penampilan pegawainya. Secara singkat dapat diartikan dewasa ini tuntutan perusahaan dalam melayani konsumen dengan sebaik-baiknya yang feedback atau timbal balik dapat dirasakan secara langsung sudah menjadi bahan pembicaraan.

Selanjutnya, tinjauan Margaretha dalam Sahib (2012) yang melihat dinamika dunia kerja dewasa ini yang mengedepankan pemenuhan kebutuhan pelayanan masyarakat maka, identifikasi kualitas layanan fisik mempunyai peranan penting dalam memperlihatkan kondisikondisi fisik pelayanan tersebut. Identifikasi kualitas layanan fisik (tangible) dapat tercermin dari aplikasi lingkungan kerja berupa:

1. Kemampuan menunjukkan prestasi kerja pelayanan dalam menggunakan alat dan perlengkapan kerja secara efisien dan efektif.

2. Kemampuan menunjukkan penguasaan teknologi dalam berbagai akses data dan inventarisasi otomasi kerja sesuai dengan dinamika dan perkembangan dunia kerja yang dihadapinya.

3. Kemampuan menunjukkan integritas diri sesuai dengan penampilan yang menunjukkan kecakapan, kewibawaan dan dedikasi kerja.

\section{Responsiveness}

Definisi Responsiveness (ketanggapan) menurut Sunyoto dan Fatonah (2015:289) yaitu suatu kebijakan untuk membantu dan memberikan pelayanan yang cepat (responsif) dan tepat kepada pelanggan, dengan penyampaian informasi yang jelas. Membiarkan konsumen menunggu persepsi yang negatif dalam kualitas pelayanan. Margaretha dalam Sahib (2012) kualitas layanan daya tanggap adalah suatu bentuk pelayanan dalam memberikan penjelasan, agar orang yang diberi pelayanan tanggap dan menanggapi pelayanan yang diterima, sehingga diperlukan adanya unsur kualitas layanan daya tanggap sebagai berikut:

1. Memberikan penjelasan secara bijaksana sesuai dengan bentuk-bentuk pelayanan yang dihadapinya. Penjelasan bijaksana tersebut mengantar individu yang mendapat pelayanan 
mampu mengerti dan menyetujui segala bentuk pelayanan yang diterima.

2. Memberikan penjelasan yang mendetail yaitu bentuk penjelasan yang substantif dengan persoalan pelayanan yang dihadapi, yang bersifat jelas, transparan, singkat dan dapat dipertanggungjawabkan.

3. Memberikan pembinaan atas bentuk-bentuk pelayanan yang dianggap masih kurang atau belum sesuai dengan syarat-syarat atau prosedur pelayanan yang ditunjukkan.

4. Mengarahkan setiap bentuk pelayanan dari individu yang dilayani untuk menyiapkan, melaksanakan dan mengikuti berbagai ketentuan pelayanan yang harus dipenuhi.

5. Membujuk orang yang dilayani apabila menghadapi suatu permasalahan yang dianggap bertentangan, berlawanan atau tidak sesuai dengan prosedur dan ketentuan yang berlaku.

\section{Kepuasan Pelanggan}

Kepuasan atau ketidakpuasan adalah perasaan senang atau tidak kecewa seseorang yang berasal dari perbandingan antara kesannya terhadap kinerja produk yang ril/aktual dengan kinerja produk yang diharapkan. (Sangadji dan Sopiah, 2013:180). Menurut Zeithmal, dkk dalam Adnyana (2016:41), terdapat empat faktor yang mempengaruhi persepsi dan ekspektasi pelanggan, yaitu sebagai berikut:

1. Apa yang didengar pelanggan dari pelanggan lainnya (word of mounth communication).

2. Ekspektasi pelanggan sangat bergantung dari karakteristik individu diman kebutuhan pribai (personal needs)

3. Pelanggan masa lalu (past experience) dalam menggunakan pelayanan dapat juga mempengaruhi tingkat ekspektasi pelanggan.

4. Komunikasi dengan pihak eksternal (eksternal communication) dari pemberi layanan memainkan peranan kunci dalam membentuk ekspektasi pelanggan.

\section{KERANGKA KONSEPTUAL DAN HIPOTESIS}

Adnyanan (2016) Tangible (bukti fisik) menyatakan bukti langsung berupa pelayananpelayanan yang dirasakan langsung oleh konsumen benar-benar diperhatkan oleh perusahaan atau konsumen untuk meningkatkan pestasi kerja perusahaan sehingga mampu menghasilkan kualitas pelayanan terbaiknya terhadp konsumen. Responsiveness (daya tanggap) merupakan upaya yang dari kantor samsat dalam memberikan tanggapan terhadap pelayanan yang diberikan kepada wajib pajak. Seperti siap membantu pelanggan, kecepatan dalam pelayanan dan komunikasi yanag lancar. Daya tanggap disini dapat berarti respon atau kesigapan pegawai kantor dalam membantu pelanggan dan memberikan pelayanan yang cepat. Semakin tinggi daya tanggap yang diperlihatkan maka permasalahan yang dihadapi akan cepat terselaikan dan akan mempengaruhi kepuasan masyarakat (Haryanto,2013).

Berdasarkan penelitian sebelumnya yaitu menurut Adnyana (2016) bahwa tangible (bukti fisik) seperti peralatan dan perlengkapan pada Samsat sangat mempengaruhi kepuasan wajib pajak. Dan didukung oleh Haryanto (2013) bahwa responsiveness (daya tanggap) seperti kesigapan dan kecepatan karyawan Samsat juga berpengaruh pada kepuasan wajib pajak. Maka semakin tinggi tangible (bukti fisik) akan semakin tinggi kepuasan. Dan semakin tinggi responsiveness (daya tanggap) maka kepuasan wajib pajak akan semakin tinggi pula.

Berdasarkan uraian di atas, untuk memperjelas hubungan antara variabel, maka dikemukakan kerangka pemikiran seperti terlihat pada gambar berikut : 


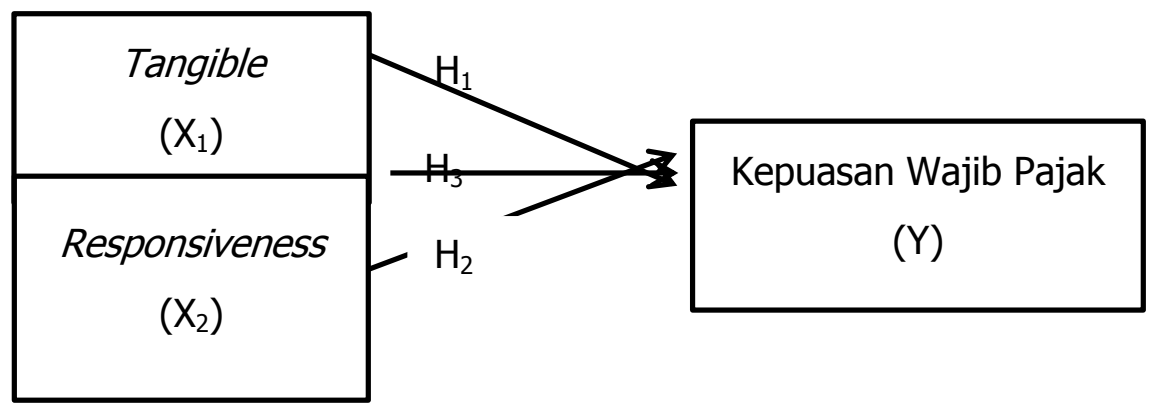

Sumber : Data yang diolah oleh penulis

Gambar 1. Kerangka Konseptual

H1 = Terdapat pengaruh yang positif dan signifikan antara Tangible terhadap kepuasan wajib pajak.

$\mathrm{H} 2$ = Terdapat pengaruh yang positif dan signifikan antara Responsiveness terhadap kepuasan wajib pajak.

H3 = Tangible dan Responsiveness berpengaruh secara bersama-sama terhadap kepuasan.

\section{METODE PENELLITIAN \\ Jenis Penlitian}

Jenis penelitian yang digunakan dalam penelitian ini yaitu penelitian kuantitatif diartikan sebagai metode penelitian yang berlandasakan pada positivisme, digunakan untuk meneliti pada populasi atau sampel tertentu, pengumpulan data menggunakan instrumen penelitian, analisis data bersifat kuantitatif/statistik, dengan tujuan untuk menguji hipotesis yang telah ditetapkan, seperti jumlah wajib pajak kendaraan bermotor di Balaraja, jumlah wajib pajak yang melakukan kewajiban membayar pajak melalui Samsat Balaraja dan skor jawaban responden terhadap pernyataan yang ada pada kuesioner.

\section{Lokasi Penelitian}

Lokasi penelitian ini dilakukan pada Samsat Keliling Balaraja yang berlokasi di Jl. Raya Serang Kp. Kalijodo Desa Parahu Kecamatan Sukamulya Kabupaten Tangerang. Provinsi Banten

Populasi dan Sampel

Populasi dalam penelitian ini adalah wajib pajak kendaraan bermotor yang terdaftar di Samsat Keliling Balaraja Kabupaten Tangerang yang sedang menjalankan kewajibannya untuk membayar pajak kendaraan bermotor yang memiliki dan memanfaatkan jasa pelayanan di Samsat Keliling Balaraja. Dalam penelitian ini populasi wajib pajak sebanyak 700 wajib pajak. Penarikan sampel dalam penelitian ini menggunakan tehnik simple random sampling. Sugiyono (2010:118) : "yakni pengambilan anggota sampel dari populasi dilakukan secara acak tanpa memperhatikan strata yang ada dalam populasi itu". Penentuan jumlah sampel dalam penelitian ini menggunakan rumus slovin dengan tiingkat eror ditetapkan $10 \%$ sehingga diperoleh jumlah sampel yang akan diteliti yaitu sebesar 88 wajib pajak yang melakukan kewajibannya di Samsat Keliling Balaraja.

\section{HASIL DAN PEMBAHASAN}

Setelah dilakukan pengumpulan data melalui penyebaran kuesioner kepada 88 orang wajib pajak yang membayar pajak kendaraan bermotornya di Kantor Samsat Balaraja diketahui bahwa jenis kelamin laki-laki mendominasi jumlah konsumen yang mengurus pajak kendaraan bermotor pada Samsat Bandar Lampung. Jumlah kelompok laki-laki sebanyak 68,2\% dan perempuan sebanyak $21,8 \%$. 


\section{Pengujian Validitas}

Pengujian validitas berguna untuk mengetahui apakah ada pertanyaan atau pertanyaan pada kuesioner yang harus dihilangkan atau diganti karena dianggap tidak relevan. Uji validitas sering digunakan untuk mengukur ketepatan suatu item

dalam kuesioner, apakah item pada kuesioner tersebut sudah tepat dalam mengukur apa yang ingin diukur (Saidani dan Arifin, 2012) Tabel 1 menunjukkan hasil pengujian validitas menggunakan metode korelasi pearson (Pearson Correlation) dimana menurut Sugiyono (2013) sebuah item pertanyaan dapat dikatakan valid apabila nilai koefisien korelasi product moment lebih besar dibandingkan dengan $r$ tabel. Pada penelitian ini dengan sampel sebanyak 88 orang maka nilai $n$ ialah $86(88-2)$ dan dengan menggunakan alpha sebesar $5 \%$ maka nikai r tabel ialah 0,2096.

\section{Pengujian Realibilitas}

Menurt Ghozali dalam Yunus (2016) pengukuran reliabilitas dibagi menjadi repeat shot dan one shot, dalam penelitian ini metode yang digunakan ialah one shot dimana pengukuran hanya sekali dan kemudian hasilnya dibandingkan dengan nilai lain. Dalam metode one shot ini sebuah variabel dapat dikatakan reliabel jika nilai perolehan Cronbach's Alpha lebih besar dibandingkan dengan 0.600 (Bahrul, 2015). Tabel 2 menunjukkan nilai Cronbach's Alpha dari variabel tangible, responsiveness, dan kepuasan telah lebih besar dibandingkan dengan 0.6, yang berarti masing-masing variabel sudah reliable.

Tabel 1 Pengujian Validitas

\begin{tabular}{ccccc}
\hline Variabel & $\begin{array}{c}\text { Item } \\
\text { Pertanyaan }\end{array}$ & $\begin{array}{c}\text { Pearson } \\
\text { Correlation }\end{array}$ & Kriteria & Keterangan \\
\hline \multirow{5}{*}{ Tangible } & X1 & 0,553 & 0,2096 & Valid \\
& X2 & 0,799 & 0,2096 & Valid \\
& X3 & 0,797 & 0,2096 & Valid \\
& X4 & 0,314 & 0,2096 & Valid \\
& X5 & 0,522 & 0,2096 & Valid \\
& X6 & 0,677 & 0,2096 & Valid \\
& X7 & 0,703 & 0,2096 & Valid \\
& X8 & 0,657 & 0,2096 & Valid \\
& X1 & 0,543 & 0,2096 & Valid \\
& X2 & 0,580 & 0,2096 & Valid \\
& X3 & 0,556 & 0,2096 & Valid \\
Responsivenees & X4 & 0,516 & 0,2096 & Valid \\
& X5 & 0,567 & 0,2096 & Valid \\
& X6 & 0,662 & 0,2096 & Valid \\
& X7 & 0,404 & 0,2096 & Valid \\
& X8 & 0,705 & 0,2096 & Valid \\
& X9 & 0,637 & 0,2096 & Valid \\
& X10 & 0,572 & 0,2096 & Valid \\
& Y1 & 0,587 & 0,2096 & Valid \\
& Y2 & 0,680 & 0,2096 & Valid \\
& Y3 & 0,464 & 0,2096 & Valid \\
& Y4 & 0,749 & 0,2096 & Valid \\
& Y5 & 0,549 & 0,2096 & Valid \\
Kepuasan & Y6 & 0,660 & 0,2096 & Valid \\
& Y7 & 0,657 & 0,2096 & Valid \\
\hline
\end{tabular}

Sumber : Data diolah SPSS Versi 22 
Tabel 2 Pengujian Realiabilitas

\begin{tabular}{cccc}
\hline Variabel & $\begin{array}{c}\text { Nilai } \\
\text { Cronbach's Alpha }\end{array}$ & Kriteria & Keterangan \\
\hline Tangilbe & 0,791 & 0,60 & Reliabel \\
Responsiveness & 0,772 & 0,60 & Reliabel \\
Kepuasan & 0,735 & 0,60 & Reliabel \\
\hline
\end{tabular}

Sumber : Data diolah SPSS Versi 22

\section{Analisa Regresi Berganda}

Berdasarkan perhitungan regresi berganda antara Tangible (X1), Responsiveness (X2) dan Kepuasan Pelanggan $(Y)$ dengan dibatu program SPSS 22 dalam perhitungannya dapat diperoleh hasil sebagai berkut:

$$
\begin{gathered}
Y=8,989+0,323 \times 1+0,231 X 2+e \\
(4,285) \quad(2,902)
\end{gathered}
$$

Berdasarkan persamaan diatas dapat diketahui bahwa:

1. Nilai B konstanta adalah 8,989 artinya jika kesadaran Tangible (X1), dan Responsiveness (X2), diabaikan, maka kepuasan wajib pajak kendaraan bermotor adalah 8,989.

2. Nilai koefisien regresi variabel tangible sebesar 0,323 bernilai positif mempunyai arti bahwa jika persepsi terhadap tangible semakin baik maka kepuasan wajib pajak selaku pengguna jasa layanan Samsat Keliling Balaraja akan meningkat.

3. Nilai koefisien regresi variabel responsiveness sebesar 0,231 bernilai positif mempunyai arti bahwa jika persepsi terhadap daya tanggap semakin baik, maka kepuasan wajib pajak juga semakin meningkat.

\section{PENGUJIAN HIPOTESIS}

Perumusan hipotesis yang diuji, dengan tingkat signifikansi yang digunakan dalam penelitian ini sebesar $5 \%$ atau a =0,05 maka hasil pengujian hipotesis tersebut adalah sebagai berikut:

\section{Uji F}

Pada Tabel 3, menunjukkan uji $\mathrm{F}$ untuk menguji semua variabel bebas pengaruh Tangible (X1), Responsiveness (X2), yang akan mempengaruhi variabel Kepuasan Konsumen (Y).

Hasil analisis regresi menggunakan SPSS 22.0 didapatkan signifikansi secara simultan p-value $=0,000<0,05$, maka dapat disimpulkan bahwa $\mathrm{HO}$ ditolak atau Ha diterima yang berarti bahwa Tangible (X1), Responsiveness (X2), secara bersama-sama berpengaruh signifikan terhadap Kepuasan Konsumen (Y).

\section{Uji T}

Uji t digunakan untuk menguji signifikansi pengaruh variabel independen terhadap variabel dependen dalam model regresi yang sudah dihasilkan. Maka digunakan uji t untuk menguji masing-masing variabel independen terhadap variabel dependen.

Tabel 4 Uji Hipotesis Secara Parsial

\begin{tabular}{ccc}
\hline Variabel & $\mathbf{T}$ & Sig \\
\hline Tangible & 7,362 & 0,000 \\
Responsiveness & 6,381 & 0,000 \\
\hline
\end{tabular}

Sumber: Data diolah menggunakan SPSS 22.0 (2017)

Hasil uji t dalam Tabel 4, menunjukkan bahwa signifikansi $p$-value $=0,000<0,05$, maka dapat disimpulkan bahwa Ha diterima dan menolak $\mathrm{HO}$ atau Tangible (X1) berpengaruh signifikan terhadap Kepuasan Konsumen $(Y)$. Dari hasil uji t pada tabel diatas dapat dilihat bahwa Responsiveness (X2) signifikansi $\mathrm{p}$-value $=0,000>0,05$, maka dapat disimpulkan bahwa $\mathrm{Ha}$ ditolak dan menerima $\mathrm{HO}$ atau Responsiveness (X2) berpengaruh signifikan terhadap Kepuasan Konsumen ( $\mathrm{Y}$ ). 


\section{PEMBAHASAN}

\section{Pengaruh Tangible Terhadap Kepuasan Wajib Pajak}

Bukti fisik dari unit pelayanan Samsat Keliling Balaraja berupa ruang tunggu yang nyaman, tempat parkir kendaraan yang memadai, perlengkapan seperti mobil keliling yang memadai, serta teknologi yang modern, akan mempengaruhi kenyamanan dan kelancaran dalam memberikan pelayanan kepada setiap masyarakat. Hal ini dapat dilihat dari sebagian besar dari responden menyatakan persetujuannya, artinya kondisi fisik pada Kantor Samsat Keliling Balaraja sudah sesuai dengan keinginan masyarakat. Semakin mendukung kondisi fisik di Kantor Samsat Keliling Balaraja maka akan mempengaruhi kepuasan.

Penelitian ini sejalan dengan penelitian Batubara,dkk (2014), dimana terdapat pengaruh positif antara tangible terhadap kepuasan. Hal itu dikarenakan semakin baik sarana prasana maka akan meningkatkan kepuasan wajib pajak.

\section{Pengaruh Responsiveness Terhadap Kepuasan Wajib Pajak}

Sesuai dengan yang dikemukakan oleh Sasongko,dkk (2013) bahwa variabel responsiveness merupakan variabel yang paling dominan terhadap kepuasan pelanggan. Kesadaran dan keinginan membantu pelanggan dan memberikan jasa yang cepat sangat amat berarti bagi para pelanggan. Dengan begitu pelanggan akan merasa sangat dihargai oleh para pegawai Samsat Keliling Balaraja, yang akan menimbulkan terciptanya rasa kepuasan.

\section{Pengaruh Tangible dan Responsiveness Terhadap Kepuasan Wajib Pajak}

Sesuai dengan apa yang dijelaskan diatas jika variabel tangible (bukti fisik) dari unit pelayanan Samsat Keliling Balaraja berupa ruang tunggu yang nyaman, tempat parkir kendaraan yang memadai, perlengkapan seperti mobil keliling yang memadai, serta teknologi yang modern, akan mempengaruhi kenyamanan dan kelancaran dalam memberikan pelayanan kepada setiap masyarakat. Dan juga variabel responsiveness (daya tanggap) para pegawai samsat keliling balaraja seperti siap membantu para wajib pajak, kecepatan pelayanan, dan komunikasi yang lancar. Artinya jika kedua varibel independen (tangible dan responsiveness) bersama-sama berjalan dengan lancar dan nyaman, maka dari itu akan menimbulkan kepuasan kepada para wajib pajak kendaraan bermotor.

\section{KESIMPULAN}

1. Tangible dan Responsiveness secara simultan berpengaruh signifikan terhadap kepuasan wajin pajak kendaraan bermotor di Samsat Keliling Balaraja.

2. Tangible berpengaruh signifikan terhadap kepuasan wajin pajak kendaraan bermotor di Samsat Keliling Balaraja.

3. Responsiveness berpengaruh signifikan terhadap kepuasan wajin pajak kendaraan bermotor di Samsat Keliling Balaraja.

\section{SARAN}

1. Perlu adanya pergantian/perbaikan nomor urut antrian dengan mesin yang lebih modern.

2. Disarankan agar dalam meningkatkan variabel bukti fisik dan daya tanggap wajib pajak kendaraan bermotor diberikan inovasi yang lebih baru lagi guna mencapai koefisien waktu seperti diberlakukannya sistem barcode sehingga petugas hanya tinggal menyecan barcode yang ada di STNK maka database akan otomatis keluar.

3. Disarankan agar Samsat Keliling Balaraja sebagai layanan kendaraan bermotor yang menerapkan sistem pelayanan prima membuat standard operating procedure (SOP). 


\section{DAFTAR PUSTAKA}

Adnyana Ketut. 2016. Tangible, Realibility, Responsiveness, Assurance, Emphaty, Pada Inovasi Layanan Terhadap Kepuasan Wajib Pajak Studi Kasus Pada Samsat Corner Tiara Dewata. Bali: Jurnal Manajemen \& Bisnis.Vol.13,No.3.

Batubara, Ginting, Lubis. 2014. Pengaruh Kualitas Pelayanan Terhadap Kepuasan Dan Word Of Mouth Mahasiswa Program Studi Diploma III Administrasi Perpajakan FISIP USU. Vol. 14, No. 02. Hal 1693-7619.

Bahrul, E, Halmi. 2015. Pengaruh Sevice Quality dan Brand Experience Terhadap Kepuasan Pelanggan (Studi Pada Pelanggan Hotel Atria, Kota Malang). Universitas Brawijaya.

Bursan, Rinaldi., Chanerie, Dhaniel. 2012. Analisis Pengaruh Kualitas Pelayanan Samsat Bandar Lapung Terhadap Kepuasan Wajib Pajak. Vol. 10, No. 2.

Creswell W. Jhon. 2016. Research Desain Pendekatan Metode Kualitatif, Kuantitatif, dan Campuran. Yogyakarta. Pustaka Belajar.

Gulla Rendy, dkk. 2015. Analisis Harga, Promosi, Dan Kualitas Pelayanan Terhadap Kepuasan Konsumen Pada Hotel Manado Grace INN. Jurnal EMBA. Vol. 3, No. 1. Hal. 13131322.

Haryanto, Edi. 2013. Kualitas Layanan, Fasilititas dan Harga Pengaruhnya Terhadap Kepuasan Pengguna Jasa Layanan Kantor Samsat Manado. Manado. Jurnal EMBA. Vol. 1., No. 3.

Manap, Abdul. 2016. Revolusi Manajemen Pemasaran. Jakarta: Mitra Wacana Media.

Rangkuti Fredi. 2015. Riset Pemasaran. Jakarta. PT Gramedia Pustaka Utama.

Rusydi dan Fathoni. 2011. Pengaruh Kualitas Pelayanan Terhadap Kepuasan Wajib Pajak Kendaraan Bermotor di Kota Batu. Jurnal Aplikasi Manajemen. Vol. 9,. No.3,. Hal 1693-5241.

Saidani. B,. Arifin, S. 2012. Pengaruh Kualitas Produk dan Kualitas Layanan Terhadap Kepuasan Konsumen dan Minat Beli pada Ranch Market. Jurnal Riset Manajemen Sains Indonesia (JRMSI) Vol 3, No. 1.

Sahib Muhammad. 2012. Pengaruh Kualitas Pelayanan Terhadap Kepuasan KonsumenPada Makasar Air Traffic Service Center MATSC PT (PERSERO) Angaksa Pura 1 Makasar. Skripsi Fakultas Ekonomi Universitas Hassanudin.

Sangadji, M.T., dan Sopiah. 2013. Perilaku Konsumen. Yogyakarta: Andi.

Sasongko, Felita, Subagio, Hartono. 2013. Pengaruh Kualitas Layanan Terhadap Kepuasan Pelanggan Restoran Ayam Penyet Ria. Jurnal Manajemen. Vol. 1, No. 2, Hal 1-7.

Sugiyono. 2013. Metode Penelitian Kuatitatif, Kualitatif, Dan R\&D. Bandung. Alfabeta.

Sunyoto, Danang., dan Susanti, E.F. 2015. Manajemen Pemasaran Jasa.Yogyakarta: Center For Academic Publishing Service. 
Tekol F.M., dan Massie . 2015. Analisis Kualitas Pelayanan Kantor SAR Kelas A Manado Terhadap Kepuasan Masyarakat, Studi Pasca Banjir Bandang di Kecamatan Tikala KotaManado.Manado:JurnalEMBA.Vol.3,No.2.

https://ejournal.unsrat.ac.id/index.php/emba/article/view/8714. Diakses 10 April $\underline{2017}$.

Yunus, Alaan. 2016. Pengaruh Service Quality (Tanggible,Empathy,Realibility, Responsiveness, dan Assurance) Terhadap Customer Satisfaction: Penelitian Pada Hotel Selera Bandung. Jurnal Manajemen. Vol. 15. No. 02. 